\title{
Regulation of Synaptic Efficacy in Hypocretin/Orexin- Containing Neurons by Melanin Concentrating Hormone in the Lateral Hypothalamus
}

\author{
Yan Rao, ${ }^{1}$ Min Lu, ${ }^{1}$ Fei Ge, ${ }^{4}$ Donald J. Marsh, ${ }^{5}$ Su Qian,,${ }^{5}$ Alex Hanxiang Wang, ${ }^{6}$ Marina R. Picciotto, ${ }^{2,3}$ and \\ Xiao-Bing Gao ${ }^{1}$ \\ Departments of ${ }^{1}$ Obstetrics/Gynecology and Reproductive Science, ${ }^{2}$ Psychiatry, and ${ }^{3}$ Neurobiology, Yale University School of Medicine, New Haven, \\ Connecticut 06520, ${ }^{4}$ Affiliated Haikou Hospital, Xiangya School of Medicine, Central South University, Haikou Municipal Hospital, Haikou, Hainan, \\ 570208, China, ${ }^{5}$ Department of Metabolic Disorders, Merck Research Laboratories, Rahway, New Jersey 07065, and ${ }^{6}$ Ursinus College, Collegeville, \\ Pennsylvania 19426-1000
}

The lateral hypothalamus (LH) is a central hub that integrates inputs from, and sends outputs to, many other brain areas. Two groups of neurons in the $\mathrm{LH}$, expressing hypocretin/orexin or melanin concentrating hormone (MCH), have been shown to participate in sleep regulation, energy homeostasis, drug addiction, motor regulation, stress response, and social behaviors. The elucidation of crosstalk between these two systems is essential to understand these behaviors and functions because there is evidence that there are reciprocal innervations between hypocretin/orexin and $\mathrm{MCH}$ neurons. In this study, we used $\mathrm{MCH}$ receptor-1 knock-out (MCHR1 KO) and wild-type (WT) mice expressing green fluorescent protein in hypocretin/orexin-containing neurons to examine the hypothesis that $\mathrm{MCH}$ modulates hypocretin/orexin-mediated effects on behavioral state and synaptic transmission in the LH. In MCHR1 KO mice, the efficacy of glutamatergic synapses on hypocretin/orexin neurons is potentiated and hypocretin-1-induced action potential firing is facilitated, potentially explaining an increased effect of modafinil observed in MCHR1 KO mice. In wild-type mice with intact MCHR1 signaling, MCH significantly attenuated the hypocretin-1-induced enhancement of spike frequency in hypocretin/orexin neurons. The MCH effect was dose dependent, pertussis toxin sensitive, and was abolished in MCHR1 KO mice. Consistent with this effect, $\mathrm{MCH}$ attenuated hypocretin1-induced enhancement of the frequency of miniature EPSCs in hypocretin/orexin neurons. These data from MCHR1 KO and WT mice demonstrate a novel interaction between these two systems, implying that $\mathrm{MCH}$ may exert a unique inhibitory influence on hypocretin/ orexin signaling as a way to fine-tune the output of the LH.

Key words: hypocretin/orexin; MCH; MCHR1; synaptic transmission; lateral hypothalamus; behavioral state; energy homeostasis

\section{Introduction}

The lateral hypothalamus (LH) is a brain structure that plays a pivotal role in various functions critical to animal survival, but the mechanisms underlying $\mathrm{LH}$ function were not easily explored until two groups of neurons, synthesizing the neuropeptides hypocretin/orexin or melanin concentrating hormone $(\mathrm{MCH})$, were identified in this region (Sawchenko, 1998). Neurons expressing hypocretin/orexin or $\mathrm{MCH}$ broadly innervate the CNS, implying that the LH is likely to participate in a greater variety of behaviors and functions via these two systems than previously thought (Bittencourt et al., 1992; Peyron et al., 1998). A growing body of evidence has demonstrated that the hypocretin/orexin and $\mathrm{MCH}$ systems are necessary for promoting positive energy

Received April 22, 2008; revised Aug. 3, 2008; accepted Aug. 5, 2008.

This work is supported by National Institutes of Health Grant DK 070723 (X.B.G.). M.R.P. was supported by National Institutes of Health Grants DA00436 and AA15632. We thank Dr. Qian Gao and Marya Shanabrough and Susan Andranovich for helpful suggestions on the manuscript.

Correspondence should be addressed to Xiao-Bing Gao, Department of Obstetrics/Gynecology, Yale University School of Medicine, 333 Cedar Street, New Haven, CT 06520. E-mail: xiao-bing.gao@yale.edu.

DOI:10.1523/JNEUROSCI.1766-08.2008

Copyright $\odot 2008$ Society for Neuroscience $\quad$ 0270-6474/08/289101-10\$15.00/0 balance (Qu et al., 1996; Sakurai et al., 1998; Cai et al., 1999). They have distinct effects on promoting wakefulness and maintaining behavioral states (Chemelli et al., 1999; Lin et al., 1999; Nishino et al., 2000; Verret et al., 2003; Modirrousta et al., 2005; Hanriot et al., 2007; Ahnaou et al., 2008), locomotor activity critical for food seeking (Marsh et al., 2002; Segal-Lieberman et al., 2003; Yamanaka et al., 2003; Zhou et al., 2005; Zhang et al., 2006), cardiovascular regulation (Messina and Overton, 2007; Samson et al., 2007), drug addiction, stress response, and social behaviors (Shi, 2004; Harris et al., 2005; Smith et al., 2005; Winsky-Sommerer et al., 2005; Borgland et al., 2006). It is not yet clear how the activity of hypocretin/orexin- and $\mathrm{MCH}$-containing neurons is coordinated to mediate the output of the LH and provide coordinate regulation of the functions and behaviors described above.

It is now clear that hypocretin/orexin exerts an excitatory effect at the cellular level via two subtypes of receptors (hcrtR1/ OX1R and hcrtR2/OX2R) in the central and peripheral nervous systems in most cases (de Lecea et al., 1998; Sakurai et al., 1998; van den Pol et al., 1998; Sutcliffe and de Lecea, 2000). MCH is a cyclic peptide with 19 amino acids. One receptor type (MCHR1, also called MCH1R, SLC-1) has been cloned in rodents, whereas 
two subtypes of receptors (SLC-1 and SLT) have been cloned in humans (Saito and Maruyama, 2006). MCH depresses forskolininduced accumulation of cAMP in non-neuronal expression systems, synaptic transmission, and voltage-dependent calcium channels in cultured hypothalamic neurons and $D_{1}$ DA receptormediated phosphorylation of GluR1 in striatal neurons (Chambers et al., 1999; Saito et al., 1999; Gao and van den Pol, 2001, 2002; Georgescu et al., 2005). The distinctive functions of hypocretin/orexin and $\mathrm{MCH}$ at the cellular level as well as a reciprocal innervation between the hypocretin/orexin and $\mathrm{MCH}$ systems suggest the possibility of crosstalk between these two systems (Guan et al., 2002; van den Pol et al., 2004).

To date, it has been shown that hypocretin/orexin depolarizes $\mathrm{MCH}$ neurons and increases synaptic transmission on $\mathrm{MCH}$ neurons (van den Pol et al., 2004); however, it is not yet clear whether and how $\mathrm{MCH}$ regulates the activity in hypocretin/ orexin neurons. In the current study, we found using MCHR1 knock-out (KO) mice and their wild-type (WT) siblings that $\mathrm{MCH}$ is critical in moderating the activity of hypocretin/orexin neurons identified by transgenic expression of green fluorescent protein (GFP). MCH appears to serve as a feedback regulator of the hypocretin/orexin system that can fine-tune the output of the LH area.

\section{Materials and Methods \\ Animals}

All mice were on the C57BL/6 genetic background and were group housed and maintained on a $12 \mathrm{~h}$ light/dark cycle (lights on at 6:00 A.M.) with food and water available ad libitum. Homozygous $M C H R 1^{-1-}$ mice on the C57BL/6 genetic background from Merck Research Laboratories were crossbred with hypocretin-GFP mice (C57BL/6 background) to obtain heterozygous breeding pairs (hypocretin-GFP/MCHRI ${ }^{+/-}$), which were used to generate hypocretin-GFP/MCHR1 $1^{+/+}$and hypocretin-GFP/MCHR1 $1^{-1-}$ mice for our experiments. PCR analysis was used to genotype offspring of the heterozygous breeding pairs as shown in Figure $1 \mathrm{~A}$. Genotyping for hypocretin-GFP-positive mice was performed as described previously (Li et al., 2002). For MCHR1 WT and KO mice, the WT and mutant alleles resulted in bands at $\sim 190$ and $\sim 260 \mathrm{bp}$, respectively. All studies were approved by the Yale University Animal Care and Use Committee and followed the National Institutes of Health Guide for the Care and Use of Laboratory Animals.

\section{Locomotor activity}

Locomotor activity was measured as described previously (Rao et al., 2007). Behavioral tests were performed during the light phase. Modafinil (Sigma-Aldrich) was dissolved in $1 \%$ dimethylsulfoxide in sterile water. All animals were habituated to the locomotor apparatus for $3 \mathrm{~d}$. This was followed by a single modafinil ( $10 \mathrm{or} 20 \mathrm{mg} / \mathrm{kg}$, i.p.) or saline injection on the fourth day. On each test day, animals were habituated to the testing room for $30 \mathrm{~min}$ before being put into locomotor activity cages and were further habituated to the test boxes for $15 \mathrm{~min}$; after habituation, animals received either a modafinil or a saline injection, and locomotor activity was monitored for $30 \mathrm{~min}$. Locomotor activity was measured in clear plastic cages $(46 \times 24 \times 20 \mathrm{~cm})$ between two rows of Opto-Max sensors (Columbus Instruments). Locomotor activity was assessed by measuring the number of beam breaks recorded during each 5 min block across the session.

\section{Double immunolabeling}

Two hours after treatment with $10 \mathrm{mg} / \mathrm{kg}$ modafinil or saline, mice (three animals per group) were deeply anesthetized and perfused transcardially with $4 \%$ paraformaldehyde. The immunostaining procedures were similarly performed as described previously (Liu and Gao, 2007). Brain sections were incubated overnight in primary antibodies for orexin-B (1: 2500; Santa Cruz Biotechnology) and c-Fos (1:1000; Oncogene) and then incubated in the secondary antibodies (1:200) conjugated to Alexa Fluor 488 and 594 (Invitrogen) for 2-3 h. The antigen absorption control for
anti-orexin-B antibody was performed by preincubation of the antibody with a blocking peptide obtained from the same vendor. Specimens were examined with an FV 300 confocal laser scanning microscope from Olympus America. For hypocretin/c-Fos-positive cell counting, three to four sections from each animal were taken, and the numbers of hypocretin/orexin neurons and c-Fos/hypocretin-positive neurons were counted and averaged. The percentage of c-Fos/hypocretin dual-labeled cells in hypocretin-positive cells was determined in each section in WT and KO mice treated with saline and modafinil $(10 \mathrm{mg} / \mathrm{kg}) . n$ reported refers to the number of samples examined in each group. An ANOVA test was used to examine the statistical significance among all groups.

\section{Hypothalamic slice preparation}

Coronal hypothalamic slices, $300 \mu \mathrm{m}$ thick, were cut from mice on postnatal days 14-21 using a vibratome. Mice expressed GFP exclusively in hypocretin/orexin neurons (Li et al., 2002; Yamanaka et al., 2003). Briefly, mice were anesthetized with ether and then decapitated. The brains were rapidly removed and immersed in cold $\left(4^{\circ} \mathrm{C}\right)$ oxygenated bath solution (containing in mM: 220 sucrose, $2.5 \mathrm{KCl}, 1 \mathrm{CaCl}_{2}, 6 \mathrm{MgCl}_{2}$, $1.25 \mathrm{NaH}_{2} \mathrm{PO}_{4}, 26 \mathrm{NaHCO}_{3}$, and 10 glucose, pH 7.3 with $\mathrm{NaOH}$ ). After being trimmed to contain only the hypothalamus, slices were maintained in a holding chamber with artificial CSF (ACSF) (bubbled with $5 \% \mathrm{CO}_{2}$ and $95 \% \mathrm{O}_{2}$ ) containing the following (in $\mathrm{mM}$ ): $124 \mathrm{NaCl}, 3 \mathrm{KCl}, 2 \mathrm{CaCl}_{2}$, $2 \mathrm{MgCl}_{2}, 1.23 \mathrm{NaH}_{2} \mathrm{PO}_{4}, 26 \mathrm{NaHCO}_{3}$, and 10 glucose, $\mathrm{pH} 7.4$ with $\mathrm{NaOH}$. Slices were transferred to a recording chamber after at least $1 \mathrm{~h}$ recovery and constantly perfused with bath solution $\left(33^{\circ} \mathrm{C}\right)$ at $2 \mathrm{ml} / \mathrm{min}$.

\section{Electrophysiology}

Extracellular recording. Extracellular recordings were made from identified hypocretin-GFP neurons with a glass electrode filled with ACSF (resistance, 2-5 M $\Omega$ ) with a multiclamp 700A amplifier (Molecular Devices). The recording electrode was propelled by a motorized micromanipulator to approach an identified hypocretin-GFP neuron. A loose seal was formed (resistance, 10-20 M $\Omega$ ) when the micropipette touched the surface of a neuron. After a $10 \mathrm{~min}$ control was recorded, drugs were applied to the recording chamber by bath application.

Whole-cell recording. Whole-cell voltage clamp (at -60 or $+40 \mathrm{mV}$ ) was performed to observe miniature or evoked postsynaptic currents with a Multiclamp 700A amplifier. The patch pipettes with a tip resistance of 4-6 M $\Omega$ were made of borosilicate glass (World Precision Instruments) with a Sutter Instruments pipette puller (P-97) and filled with a pipette solution containing the following (in $\mathrm{mM}$ ): $135 \mathrm{~K}$-gluconate (or Cs-gluconate), $2 \mathrm{MgCl}_{2}, 10$ HEPES, 1.1 EGTA, $2 \mathrm{Mg}$-ATP, $10 \mathrm{Na}_{2}$ phosphocreatine, and $0.3 \mathrm{Na}_{2}-\mathrm{GTP}, \mathrm{pH} 7.3$ with $\mathrm{KOH}$. After a gigaohm seal and whole-cell access were achieved, the series resistance (between 20 and $40 \mathrm{M} \Omega$ ) was partially compensated by the amplifier. Miniature EPSCs (mEPSCs) were recorded under voltage clamp at $-60 \mathrm{mV}$ in the presence of tetrodotoxin (TTX) $(1 \mu \mathrm{M})$ and bicuculline $(30 \mu \mathrm{M})$. To monitor evoked EPSCs, the stimulating electrode was placed at least 125 $\mu \mathrm{m}$ laterally from the recorded neurons. Evoked EPSCs recorded in hypocretin/orexin neurons under voltage clamp at $+40 \mathrm{mV}$ in the presence of picrotoxin $(50 \mu \mathrm{M})$ contained both AMPA and NMDA components, and AMPA receptor (AMPAR)-carried EPSC was obtained by applying DL-2-amino-5-phosphonovaleric acid (AP-5) $(50 \mu \mathrm{M})$ to the recorded neurons. The NMDA receptor (NMDAR)-carried component of the EPSC was determined by subtracting the AMPA component from the whole EPSC recorded before the application of AP-5. Both input resistance and series resistance were monitored throughout the experiments. Only those recordings with stable series resistance and input resistance were accepted. Drugs were applied to the recording chamber via bath application after at least $10 \mathrm{~min}$ of control recording.

All data were sampled at $3-10 \mathrm{kHz}$ and filtered at $1-3 \mathrm{kHz}$ with an Apple Macintosh computer using Axograph 4.9 (Molecular Devices). Electrophysiological data were analyzed with Axograph 4.9 and plotted with Igor Pro software (WaveMetrics). Miniature postsynaptic currents were detected and measured with an algorithm in Axograph 4.9 (Gao and van den Pol, 2001; Rao et al., 2007). The frequency of mEPSCs was normalized by comparing the average mEPSC frequency for a $3 \mathrm{~min}$ plateau after drug application with that for 5 min just before drug application. 
A

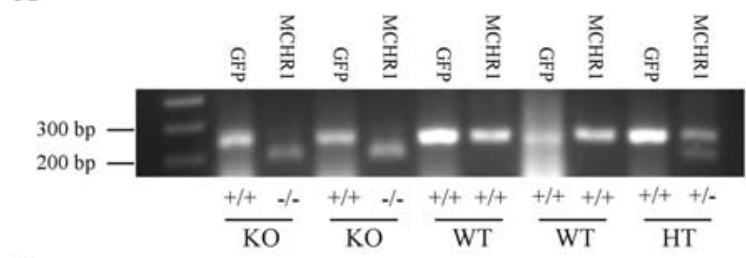

B

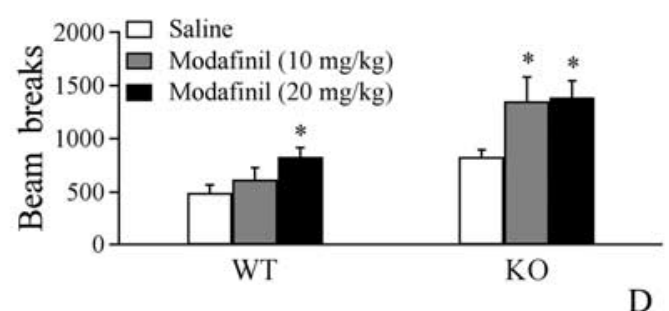

$\mathrm{C}$

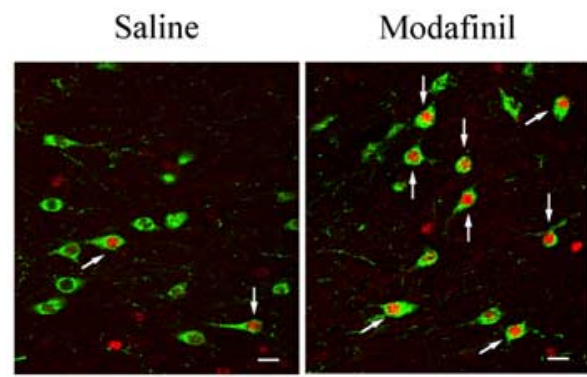

D

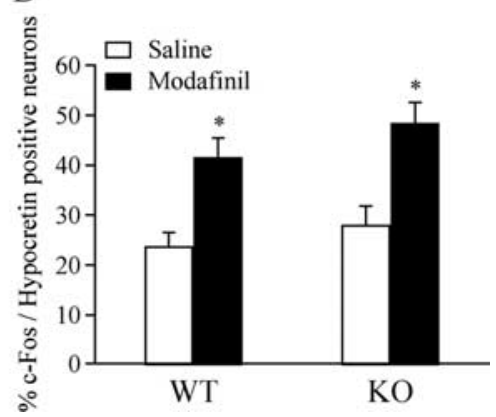

Figure 1. Sensitization to modafinil-induced increase in locomotor activity during the light phase in $M C H R 1^{-/-}$/hypocretinGFP mice. $A$, DNA bands demonstrate the genotyping of $M C H R 1^{-/-} /$hypocretin-GFP (KO), MCHR1 ${ }^{+/+} /$hypocretin-GFP (WT), and $M C H R 1^{+/-}$/hypocretin-GFP (HT) mice. $B$, Pooled data of beam breaks recorded 30 min after administration of saline or modafinil (10 or $20 \mathrm{mg} / \mathrm{kg}$ ) from all tested WT and MCHR1 KO mice. ${ }^{*} p<0.05$. C, Photomicrographs demonstrate double labeling (indicated by arrows) of hypocretin/orexin (green) and c-Fos (red) in hypocretin/orexin neurons in saline-treated (left) and modafinil-treated (right) MCHR1 KO mice. Scale bar, $15 \mu \mathrm{m}$. D, Pooled data showing the percentage of c-Fos-positive hypocretin/ orexin neurons from WT and MCHR1 K0 mice treated with modafinil $(10 \mathrm{mg} / \mathrm{kg}) .{ }^{*} p<0.05 ;{ }^{* *} p<0.01$.

Hypocretin-1/orexin A and MCH were obtained from Phoenix Pharmaceutical. Bicuculline, D-AP-5, picrotoxin, and pertussis toxin (PTX) were purchased from Sigma. SKF81297 (6-chloro-2,3,4,5-tetrahydro-1phenyl-1 $H$-3-benzazepine hydrobromide) was obtained from Tocris Cookson. TTX was obtained from Alomone Labs.

\section{Results}

Sensitization to hypocretin/orexin-mediated wakefulnesspromoting effects in MCHR1 KO mice

Hypocretin/orexin neurons in the LH have been demonstrated as one of several systems through which modafinil exerts its wakefulness-promoting effects (Scammell et al., 2000). Our recent results have shown that modafinil promotes wakefulness by potentiating synaptic transmission in hypocretin/orexin neurons (Rao et al., 2007). Therefore, it is conceivable that any manipulation altering the activity of hypocretin/orexin neurons should be able to modify the behavioral response to modafinil in animals. We hypothesized that, if $\mathrm{MCH}$ could modulate the activity of hypocretin/orexin neurons, it may interfere with the behavioral state (wakefulness) of the animal exposed to modafinil. To test this hypothesis, we examined the effect of modafinil on locomotor activity in MCHR1 KO and WT mice during the light phase, which is relevant to their sleep-wake states. Consistent with previous results (Marsh et al., 2002; Smith et al., 2005), MCHR1 KO mice exhibit elevated basal locomotor activity as measured by the total beam breaks over $30 \mathrm{~min}$ (Fig. 1, open bars). The administration of modafinil $(10 \mathrm{mg} / \mathrm{kg}$, i.p.) significantly increased the locomotor activity in $\mathrm{KO}$ mice (saline, $832 \pm 62.5$; modafinil,
$1353 \pm 225 ; p<0.05)$ but not in WT mice (saline, $492 \pm 72.7$; modafinil, $618 \pm 109$; $p>0.05)$ as reported previously by Simon et al. (1994). At a dose of $20 \mathrm{mg} / \mathrm{kg}$, modafinil produced significant increase of locomotor activity in both WT and KO mice (WT, $830.88 \pm 82.48, n=8, p<$ $0.05 ; \mathrm{KO}, 1386.4 \pm 157.05, n=8, p<$ $0.05)$. To determine whether the activation of hypocretin/orexin neurons was correlated with the enhanced locomotor activity by modafinil at $10 \mathrm{mg} / \mathrm{kg}$ in MCH1R KO mice, we examined the expression of the immediate early gene protein c-Fos in hypocretin/orexin neurons after treatment with modafinil $(10 \mathrm{mg} / \mathrm{kg})$ through double immunolabeling for hypocretin and c-Fos (Fig. 1C). The percentage of c-Fos/hypocretin dual-labeled cells in hypocretin-positive cells was determined in WT and KO mice treated with saline and modafinil $(10 \mathrm{mg} / \mathrm{kg})$. The cFos/hypocretin dual-labeled neurons were $23.8 \pm 2.72 \%(n=17, \mathrm{WT})$ and $28.2 \pm$ $3.69 \%(n=19, \mathrm{KO})$ in saline-treated mice. After treatment with modafinil, c-Fos/hypocretin-positive neurons were $41.7 \pm 3.75 \%(n=22)$ and $48.5 \pm 4.09 \%$ $(n=24)$ in WT and KO mice. A significant increase in the number of c-Fos/ hypocretin-positive neurons was observed in modafinil-treated mice $(F=$ 9.283; $p<0.0001$, ANOVA) (Fig. $1 D$ ). In $\mathrm{KO}$ mice, modafinil treatment induces a significant increase in c-Fos expression in hypocretin/orexin neurons $(p<0.01$, post test). It should be noted that the percentage of $c$-Fos/hypocretin-positive neurons also increased in WT mice ( $p<0.05$, post hoc test), although there was not a significant increase in locomotor activity after treatment with $10 \mathrm{mg} / \mathrm{kg}$ modafinil in these mice. Although modafinil has been shown to act broadly in the CNS, these data suggest that hypocretin/ orexin neurons participate in the sensitization to modafinilinduced wake-promoting effects in MCHR1 KO mice.

\section{Decreased threshold of activation in hypocretin/orexin neurons from MCH1R KO mice}

There was no significant difference in resting membrane potential (WT, $-54.79 \pm 1.09 \mathrm{mV}, n=14 ; \mathrm{KO},-53.94 \pm 1.13 \mathrm{mV}$, $n=13$ ), action potential threshold (WT, $-30.77 \pm 1.09 \mathrm{mV}, n=$ $15 ; \mathrm{KO},-30.12 \pm 1.19 \mathrm{mV}, n=15$ ), and input resistance (WT, $590.77 \pm 48.77 \mathrm{M} \Omega, n=30 ; \mathrm{KO}, 560.32 \pm 35.42 \mathrm{M} \Omega, n=37$ ) in hypocretin/orexin neurons between WT and KO mice. This allowed us to ask what factors might contribute to the excitability and firing pattern of hypocretin/orexin neurons and therefore to their ability to promote wakefulness. To keep intracellular content intact during long-term recording, we used extracellular recording to monitor action potentials in hypocretin/orexincontaining neurons. We found that hypocretin-1 (300 nM) increased the frequency of spikes (action currents, the count part of action potential recorded under voltage clamp held at $0 \mathrm{mV}$ ) in hypocretin/orexin-containing neurons from WT mice as reported by Li et al. (2002). More interestingly, the increment in 
spike frequency in response to hypocretin-1 was significantly higher in MCH1R KO mice than in WT mice (WT, $214.6 \pm 18.6 \%$ of control, $n=13 ; \mathrm{KO}$, $367.5 \pm 57.8 \%$ of control, $n=14 ; p<$ 0.05) (Fig. 2), suggesting that the hypocretin-1-mediated effect on action potential generation in hypocretin/orexin neurons is potentiated in MCHR1 KO mice. Because glutamatergic synaptic transmission onto hypocretin/orexin neurons is essential for action potential firing and function of the hypocretin/orexin system ( $\mathrm{Li}$ et al., 2002; Horvath and Gao, 2005), we compared the basal parameters of synaptic transmission onto hypocretin/ orexin neurons in slices from MCH1R KO and WT mice. mEPSCs were obtained in the presence of TTX $(0.5 \mu \mathrm{M})$ and bicuculline $(30 \mu \mathrm{M})$ under voltage clamp $(-60$ $\mathrm{mV}$ ). The frequency of mEPSCs was comparable between WT and KO mice (WT, $6.27 \pm 0.65 \mathrm{~Hz}, n=23 ; \mathrm{KO}, 6.04 \pm 0.74$ $\mathrm{Hz}, n=18 ; p>0.05$ ) (Fig. $3 A, B$ ), whereas cumulative probability of the amplitude of mEPSCs in KO mice was shifted significantly to the right ( $p<0.001$, Kolmogorov-Smirnov test) (Fig. 3C), suggesting that postsynaptic glutamate receptors are likely to be upregulated on hypocretin/ orexin neurons in MCH1R KO mice. We then examined the relative contributions of AMPARs and NMDARs to evoked EPSCs in hypocretin/orexin neurons in slices from WT and KO mice. Evoked EPSCs were recorded under voltage clamp at $+40 \mathrm{mV}$ in the absence and then the presence of the selective NMDA receptor antagonist AP-5 (50 $\mu \mathrm{M}$ ) as described previously (Rao et al., 2007). As shown in Figure 3, $D$ and $E$, the AMPAR/NMDAR ratio from $\mathrm{KO}$ mice increased significantly compared with neurons from WT mice (KO, $3.27 \pm$ 0.33, $n=10$; WT, $2.5 \pm 0.27, n=10 ; p<0.05)$, indicating an enhancement of AMPAR contribution to EPSCs in hypocretin/ orexin neurons in MCH1R KO mice. In contrast, both the frequency and amplitude of mIPSCs recorded in hypocretin/orexin neurons were identical in WT and KO mice (Fig. $3 F-H)$.

It has been shown that dopaminergic pathways play a substantial role in promoting functions mediated by hypocretin/orexin neurons, particularly in wakefulness promotion (Nakamura et al., 2000; Narita et al., 2006; Rao et al., 2007). Dopamine $D_{1}$ receptor activation increases excitatory synaptic transmission onto hypocretin/orexin neurons presynaptically and participates in the promotion of prolonged wakefulness in rodents (Alberto et al., 2006; Rao et al., 2007). We therefore determined whether dopaminergic excitation of hypocretin/orexin neurons was altered in MCH1R KO mice. Consistent with a previous report by Alberto et al. (2006), bath application of the $D_{1}$ agonist SKF81297 $(50 \mu \mathrm{M})$ increased the frequency of mEPSCs in hypocretin/orexin neurons in WT mice $(127.1 \pm 4.5 \% ; n=11 ; p<0.001$, ANOVA), and the frequency of mEPSCs was also increased in $\mathrm{KO}$ mice $(154 \pm 10.7 \% ; n=11 ; p<0.001$, ANOVA) (Fig. $4 A, B)$. The $\mathrm{D}_{1}$-mediated increase in mEPSC frequency was significantly higher in neurons from KO mice compared with WT mice $(p<$ 0.05) (Fig. 4C). The amplitude of mEPSCs did not change in the presence of SKF81297 in hypocretin/orexin neurons from either
KO or WT mice (data not shown), in line with what had been reported previously (Alberto et al., 2006). These data suggest that the absence of MCHR1-mediated signaling leads to an upregulation of $\mathrm{D}_{1}$ receptor-triggered glutamate release onto hypocretin/ orexin neurons as well as potentiation of AMPA receptor trafficking to the cell surface in MCHR1 KO mice. It also suggests that $\mathrm{MCH}$ may normally exert inhibitory effects on hypocretin/orexin neuronal activity.

\section{MCH blocks hypocretin-1-mediated enhancement of action potential generation in hypocretin/orexin neurons}

Because hypocretin-1-mediated stimulation of hypocretin/ orexin neurons was enhanced in MCHR1 KO mice (Fig. 2), we explored the effect of $\mathrm{MCH}$ on the frequency of spontaneous action currents in neurons from WT mice. We found that $\mathrm{MCH}$ alone induced little change in spike frequency in all 17 tested hypocretin/orexin neurons ( $\mathrm{MCH}$ at $1 \mu \mathrm{M}, 95.2 \pm 7.1 \%$ of control; washout, $99.4 \pm 2.7 \%$ of control; $n=17 ; p>0.05$, ANOVA) (Fig. 5A, $B$ ), suggesting that $\mathrm{MCH}$ does not exert a significant inhibition on baseline action potential generation in hypocretin/ orexin neurons in brain slices. However, although MCH by itself had no obvious effects on spike firing, it inhibited the increase in spike frequency caused by hypocretin-1 (hypocretin-1 at $300 \mathrm{nM}$, $192.8 \pm 27.7 \%$ of control; hypocretin- 1 at $300 \mathrm{~nm}$ plus $\mathrm{MCH}$ at 1 $\mu \mathrm{M}, 112.7 \pm 29.1 \%$ of control; hypocretin- 1 after $\mathrm{MCH}$ washout, $238.3 \pm 40.5 \%$ of control; baseline after final washout, $130.5 \pm$ $8.6 \%$ of control; $n=9$ ). Statistical analysis suggested that the frequency of action currents was significantly decreased in the presence of hypocretin-1 plus MCH compared with hypocretin-1 alone ( $p<0.05$, paired $t$ test) (Fig. $5 E$ ). $\mathrm{MCH}$ at a lower concentration $(0.1 \mu \mathrm{M})$ induced little inhibition of the hypocretin-1- 
A

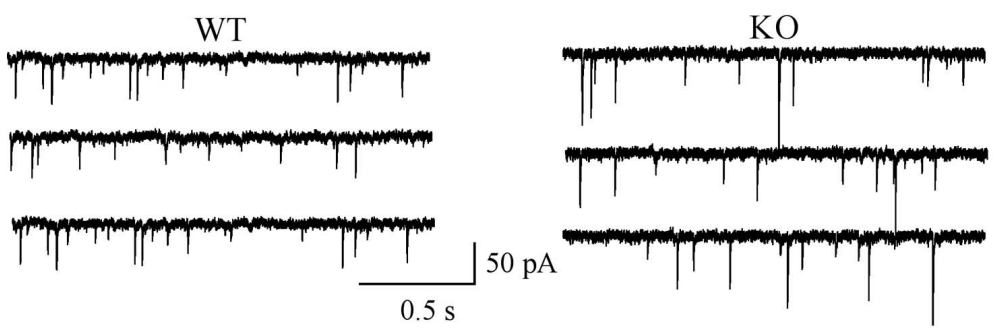

B

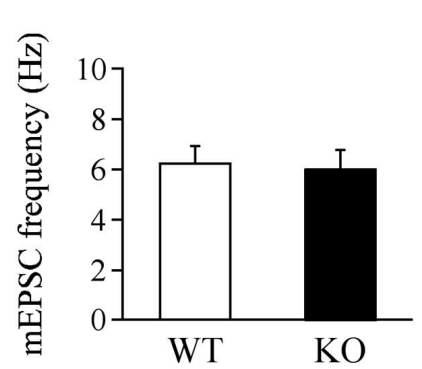

D

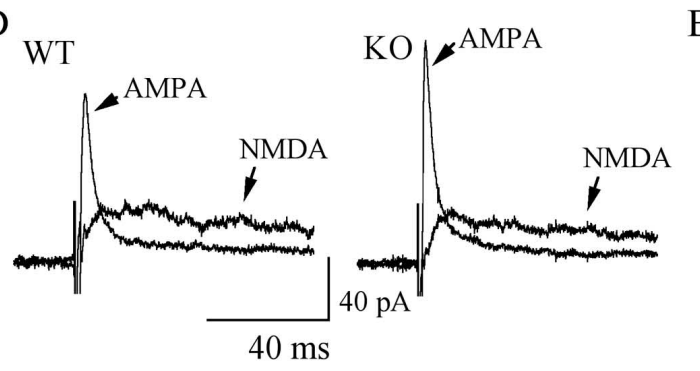

F

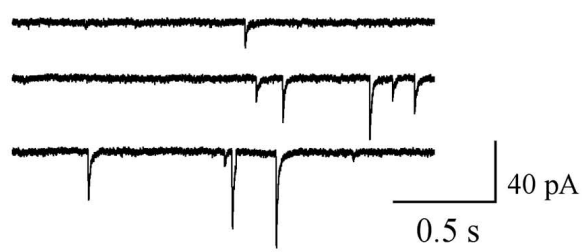

G

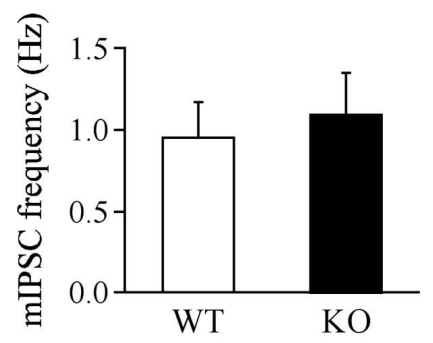

$\mathrm{C}$

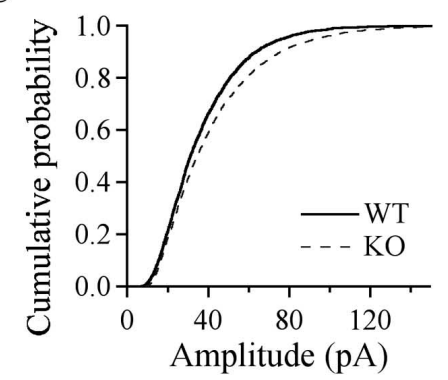

E

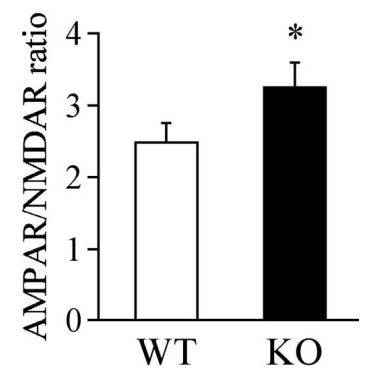

KO

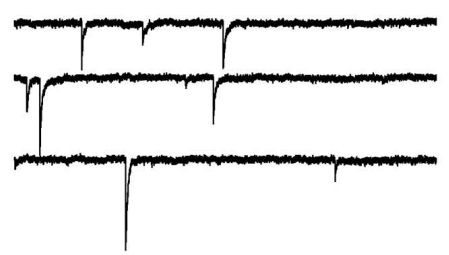

$\mathrm{H}$

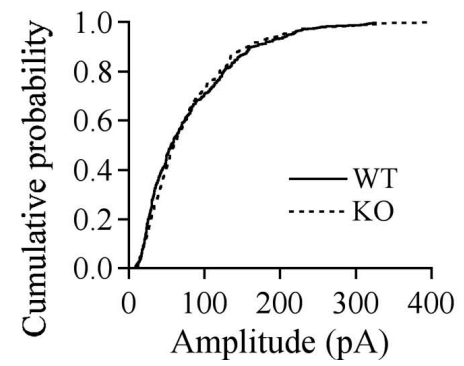

Figure 3. Upregulation of glutamatergic synaptic transmission in hypocretin/orexin neurons from MCHR1 K0 mice. mEPSCs were recorded in hypocretin/orexin neurons under voltage clamp in the presence of TTX and bicuculline. $\boldsymbol{A}$, Sample traces of $\mathrm{mEPSC}$ recorded in hypocretin/orexin neurons from MCHR1 WT and KO mice. $\boldsymbol{B}$, Pooled data for the frequency of mEPSCs recorded in hypocretin/orexin neurons from MCHR1 WT and KO mice show no significant difference between WT and KO mice. C, Cumulative probability of the amplitude of mEPSC events recorded in hypocretin/orexin neurons from MCHR1 WT and K0 mice indicates a significant right shift in $\mathrm{KO}$ mice, suggesting enhancement of the amplitude of mEPSCs in these mice ( $p<0.05$, KolmogorovSmirnov test). $\boldsymbol{D}$, Sample traces of evoked EPSCs carried by AMPA and NMDA receptors in hypocretin/orexin neurons from MCHR1 WT (left) and KO (right) mice. E, Pooled data for AMPAR/NMDAR ratio in all tested hypocretin/orexin neurons from MCHR1 WT and KO mice. ${ }^{*} p<0.05, t$ test. $\boldsymbol{F}$, Sample traces of mIPSCs recorded in hypocretin/orexin neurons from MCHR1 WT and K0 mice. $\mathbf{G}$, Pooled data for the frequency of mIPSCs recorded in hypocretin/orexin neurons from MCHR1 WT and K0 mice show no significant difference between WT and KO mice. $\boldsymbol{H}$, Cumulative probability of the amplitude of mIPSC events recorded in hypocretin/orexin neurons from MCHR1 WT and KO mice indicates no changes in the amplitude of mIPSCs in K0 mice ( $p>0.05$, KolmogorovSmirnov test).

induced increase in the frequency of spikes (hypocretin-1 at $300 \mathrm{~nm}, 213.4 \pm 33.6 \%$ of control; hypocretin- 1 at $300 \mathrm{~nm}$ plus $\mathrm{MCH}$ at $0.1 \mu \mathrm{M}, 188.0 \pm 31.2 \%$ of control; $n=7$; $p>0.05$, paired $t$ test) (Fig. $5 E$ ). Thus, the $\mathrm{MCH}$-mediated effect is dose dependent.

To verify the involvement of MCHR1 in $\mathrm{MCH}$-mediated inhibition of spike frequency enhancement by hypocretin-1, $\mathrm{MCH}(1 \mu \mathrm{M})$ was applied to LH slices prepared from MCH1R KO mice. The spike frequency of hypocretin/orexin neurons in the presence of hypocretin-1 alone $(372.8 \pm 60.4 \%$ of control; $n=6)$ and in the presence of hypocretin-1 plus $\mathrm{MCH}$ (369.4 $\pm 64.4 \%$ of control; $n=6$ ) was comparable ( $p>0.05$, paired $t$ test) (Fig. $5 F)$, demonstrating that the $\mathrm{MCH}$ mediated inhibitory effect was abolished in MCHR1 KO mice.

MCHR1 is thought to couple to $\mathrm{G}_{\mathrm{i} / \mathrm{o}^{-}}$ proteins (Bächner et al., 1999; Chambers et al., 1999; Saito et al., 1999; Gao and van den Pol, 2001), which can activate multiple intracellular and extracellular signaling pathways (Hawes et al., 2000; Pissios et al., 2003), whereas hypocretin/orexin receptors couple to the $G_{\mathrm{q}}$ pathway (Sakurai et al., 1998). To identify the signaling pathway involved in the effects of $\mathrm{MCH}$ on spike frequency of hypocretin/orexin neurons, we treated slices with PTX, which inhibits the $G_{i / o}$-mediated activity. Hypocretin-1 (300 nM) could still enhance spike frequency $(1.56 \pm 0.44 \mathrm{~Hz}, n=7)$ in slices preincubated with PTX (500 ng/ml) for $3 \mathrm{~h}$ in all tested neurons (270.8 \pm $32.5 \%$ of control) (Fig. $6 A-C$ ), but the ability of MCH to block the effect of hypocretin-1 was abolished (hypocretin-1 at $300 \mathrm{~nm}$ plus $\mathrm{MCH}$ at $1 \mu \mathrm{M}, 295.7 \pm 43.6 \%$ of control; washout, $154.7 \pm 20.0 \%$ of control; $n=7$ ), indicating that $\mathrm{MCH}$ induced inhibition is PTX sensitive and is likely mediated by the $G_{i / o}$ pathway in brain slices.

MCH modulates synaptic efficacy of glutamatergic transmission in hypocretin/orexin neurons Previous reports have suggested that glutamatergic transmission onto hypocretin/ orexin neurons makes a major contribution to the excitation and generation of action potentials in these neurons (Li et al., 2002; Horvath and Gao, 2005) and that hypocretin-1 increases the frequency but not the amplitude of mEPSCs in hypocretin/orexin neurons via putative glutamatergic interneurons in the $\mathrm{LH}$ ( $\mathrm{Li}$ et al., 2002). MCH was therefore applied to the recording chamber after a stable recording of mEPSCs was obtained to determine 
whether $\mathrm{MCH}$ could modulate the synaptic efficacy of glutamatergic transmission onto hypocretin/orexin neurons. $\mathrm{MCH}(1 \mu \mathrm{M})$ did not inhibit the basal frequency of mEPSCs (baseline frequency of mEPSCs, $5.7 \pm$ $1.1 \mathrm{~Hz}$; frequency of mEPSCs in the presence of $\mathrm{MCH}$ at $1 \mu \mathrm{M}, 105.7 \pm 9.4 \%$ of control; $n=7 ; p>0.05, t$ test) (Fig. $7 A$, inset). However, the increase in the frequency of $\mathrm{mEP}$ SCs by hypocretin-1 over control was significantly reduced by addition of $\mathrm{MCH}$ (baseline frequency of mEPSCs, $4.6 \pm 0.3$ $\mathrm{Hz}$; frequency of mEPSCs in the presence of hypocretin- 1 at $300 \mathrm{nM}, 156.1 \pm 11.7 \%$ of control; hypocretin-1 at $300 \mathrm{nM}$ plus $\mathrm{MCH}$ at $1 \mu \mathrm{M}, 112.9 .2 \pm 5.2 \%$ of control; $n=7$; $p<0.05$, paired $t$ test) (Fig. $7 A-C$ ). There was no significant difference in the amplitude of mEPSCs recorded in slices treated with hypocretin-1 plus $\mathrm{MCH}$ compared with mEPSC events recorded in the presence of hypocretin-1 alone (data not shown). These results indicate that $\mathrm{MCH}$ modulates the synaptic efficacy of glutamatergic synaptic transmission onto hypocretin/orexin neurons presynaptically.

\section{Discussion}

In this study, we demonstrate for the first time that $\mathrm{MCH}$ exerts an inhibitory effect on hypocretin/orexin neurons as well as on modafinil-induced wakefulness, which may serve as feedback in determining the output of the LH. The potentiation of the effect of modafinil on wakefulness in MCHR1 KO mice may be attributable to increased efficacy of glutamatergic transmission onto hypocretin/orexin neurons in the absence of MCHR1-mediated signaling. In wild-type animals, $\mathrm{MCH}$ depresses hypocretin/orexin-induced action potential generation and glutamatergic transmission onto hypocretin/orexin neurons but not the basal activity of these neurons.

\section{Upregulation of glutamatergic transmission in MCHR1 KO mice}

MCHR1 KO mice show a number of distinct behavioral phenotypes when compared with WT littermates, including hyperactivity and increased sensitivity to the addictive drug D-amphetamine (Marsh et al., 2002; Smith et al., 2005, 2006, 2008). It was originally suggested that the hyperactivity and amphetamine phenotypes were attributable to sensitization of the DA system in MCHR1 KO mice (Smith et al., 2005, 2008), but our new evidence suggests that changes in hypocretin/orexin neurons in the LH area are also likely to contribute to the increased activity of MCHR1 KO mice. Our results further suggest that MCHR1 KO mice are sensitized to treatments, such as modafinil administration, leading to wakefulness, possibly through increased activation of hypocretin/orexin neurons. We demonstrate here that glutamatergic synapses on hypocretin/orexin neurons are potentiated in MCHR1 KO mice and that there appears to be both an upregulation of AMPA-type glutamate receptors to synapses on hypocretin/orexin neurons and an increased response of presynaptic terminals innervating hypocretin/orexin neurons to $\mathrm{D}_{1}$-type $\mathrm{DA}$ receptors. These results suggest that upregulated glutamatergic transmission onto hypocretin/orexin neurons may contribute to the sen- sitization of the DA system reported previously (Smith et al., 2005, 2008), which may be the consequence of the altered output of neurons in the LH. Together, our data suggest that the sensitization of MCHR1 KO mice to the wakefulness-promoting agent modafinil may be attributable, at least in part, to increased glutamatergic transmission onto hypocretin/orexin neurons, raising the intriguing question of how MCH modulates the function of hypocretin/orexin neurons in MCHR1-intact animals.

\section{MCH-mediated inhibition of hypocretin/orexin neurons}

$\mathrm{MCH}$ has been shown to activate G-protein-coupled receptors in non-neuronal cell lines and cultured neurons (Bächner et al., 1999; Saito et al., 1999; Gao and van den Pol, 2001, 2002). Our knowledge about the function of $\mathrm{MCH}$ in the CNS at the cellular level is still limited, although a role for $\mathrm{MCH}$ has been suggested in a variety of functions (Shi, 2004). We demonstrate here for the first time that $\mathrm{MCH}$ has an inhibitory effect on action potential generation and glutamatergic synaptic transmission in hypocretin/orexin neurons in LH slices. The MCH-mediated inhibition was dose dependent, absent in MCHR1 KO mice, and blocked in slices pretreated with PTX, consistent with reports that the $G_{i / o}$ pathway is activated by $\mathrm{MCH}$ receptor stimulation in cell lines (Chambers et al., 1999; Lembo et al., 1999; Saito et al., 1999). Stimuli originating from both local (hypocretinergic) and afferent (dopaminergic) pathways have been demonstrated to increase synaptic activity and spike frequency of hypocretin/orexin neurons by enhancing the release of glutamate from neurons 
A

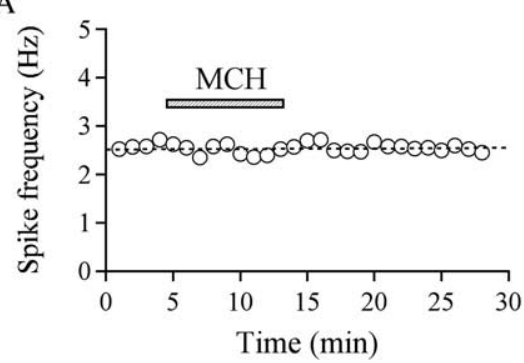

$\mathrm{B}$

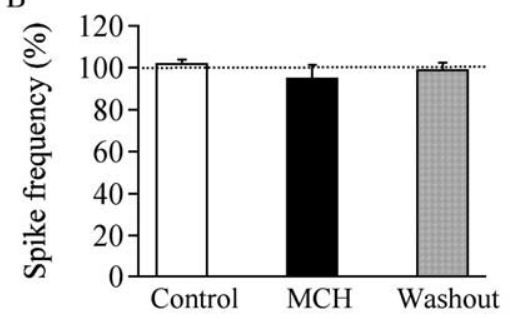

C

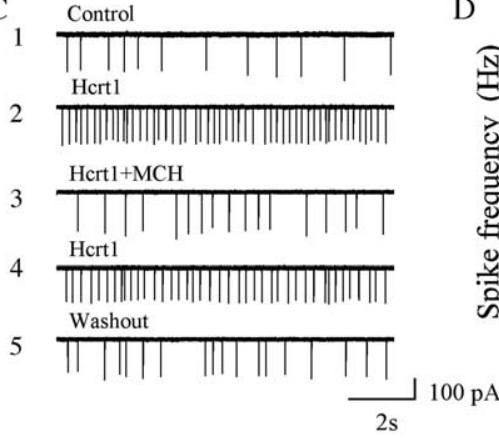

$\mathrm{E}$

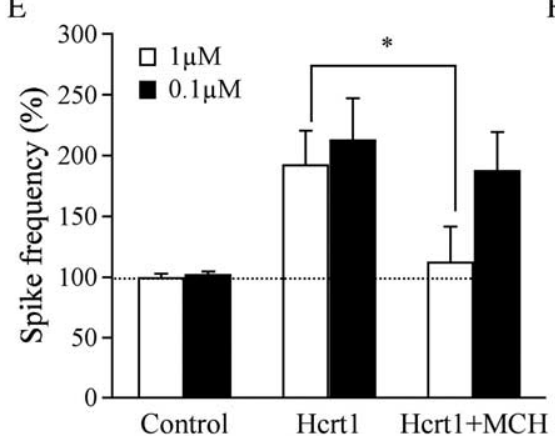

$\mathrm{D}$

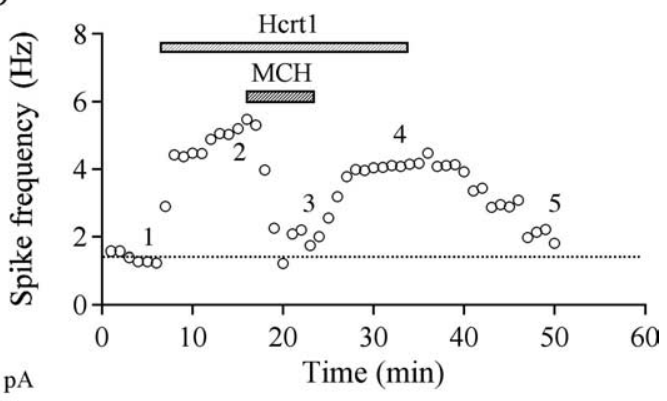

$\mathrm{F}$

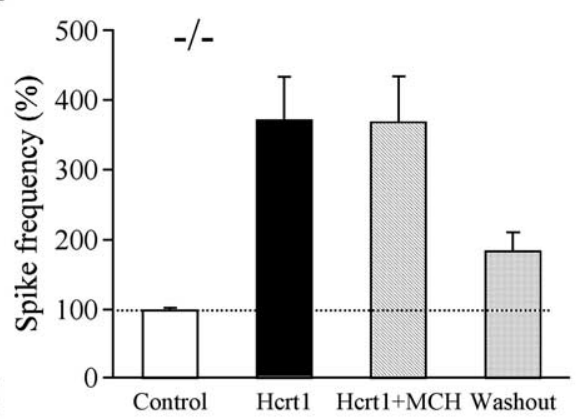

Figure 5. MCH reverses hypocretin-1-induced enhancement of action potentials in hypocretin/orexin neurons. $\boldsymbol{A}, \boldsymbol{B}$, The time course of a typical experiment and pooled data show that $\mathrm{MCH}(1 \mu \mathrm{M})$ applied to the recorded neurons did not attenuate the basal frequency of spikes in hypocretin neurons. $C, D, M C H(1 \mu \mathrm{M})$ applied to the recorded neurons attenuated hypocretin-1-induced enhancement of spike frequency in hypocretin/orexin neurons. This attenuation was reversible during the removal of $\mathrm{MCH}$. Sample traces recorded in our experiments are presented in $\boldsymbol{C}$ and the time course of a typical experiment is shown in $\boldsymbol{D}$. Time points at which raw traces were taken are indicated by $1-5$. E, Pooled data for the frequency of spikes show the dose dependency of MCH-mediated inhibition of hypocretin-1-induced firing of spikes in hypocretin/orexin neurons. ${ }^{*} p<0.05$.F, Pooled data from experiments with MCHR1 $\mathrm{KO}$ mice indicate that the MCH-mediated inhibitory effect was abolished in $\mathrm{KO}$ mice.

in cultured LH neurons (Gao and van den Pol, 2001), suggesting that there is a difference between the effects of $\mathrm{MCH}$ in acute slices and in cultured neurons. We believe that results from acute brain slices are more relevant to physiological conditions than those from cultured neurons.

It is intriguing to note the potentiation of glutamatergic transmission at the postsynaptic sites attributable to upregulation (likely enhanced trafficking) of AMPA receptors in hypocretin/orexin neurons in MCHR1 KO mice. These results suggest possible postsynaptic mechanisms for MCH-mediated inhibition of hypocretin/orexin neurons, in line with previous observations showing $\mathrm{MCH}$ leads to dephosphorylation of GluR1 (Georgescu et al., 2005). Alternatively, the upregulation of AMPA activity may represent a long-term consequence of the relief of $\mathrm{MCH}$-mediated inhibition of hypocretin/ orexin neurons. It is reasonable to postulate that a sustained increase in glutamatergic transmission (such as the enhanced presynaptic release of glutamate observed here) onto hypocretin/orexin neurons and the removal of possible postsynaptic effects on these neurons in MCHR1 KO mice may lead to potentiation of synaptic efficacy at postsynaptic sites in hypocretin/orexin neurons, a process resembling experiencedependent synaptic plasticity in these neurons (Rao et al., 2007). Thus, the upregulation of efficacy of glutamatergic synapses on hypocretin/orexin neurons may account for behavioral phenotypes related to wakefulness in MCHR1 KO mice, such as increased locomotor activity during the day in these nocturnal rodents (Marsh et al., 2002; Smith et al., 2005). The current data implicate $\mathrm{MCH}$ as a feedback regulator modulating the efficacy of glutamatergic synapses in hypocretin/orexin neurons in the LH area. with synaptic contacts on hypocretin/orexin neurons (Li et al., 2002; Alberto et al., 2006). We demonstrate in this study that $\mathrm{MCH}$ might reduce glutamate release at presynaptic terminals to antagonize the excitatory effects on hypocretin/orexin neurons.

We did not detect MCH-mediated inhibition of baseline action potential generation or glutamatergic synaptic transmission in hypocretin/orexin neurons in brain slices in the current study; rather, we demonstrate that $\mathrm{MCH}$ inhibits hypocretin/orexininduced action potential generation and glutamatergic transmission in hypocretin/orexin neurons in brain slices. These results are consistent with a report in striatal neurons that $\mathrm{MCH}$ completely blocked the phosphorylation of GluR1 induced by activation of $\mathrm{D}_{1} \mathrm{DA}$ receptors but not the basal phosphorylation of GluR1 (Georgescu et al., 2005). Because MCH neurons are usually silent at the resting state and excited by the application of hypocretin (Eggermann et al., 2003; van den Pol et al., 2004), our new data and previous evidence tend to imply that $\mathrm{MCH}$ may exert its functions in a homeostatic manner in intact animals. In our previous studies, $\mathrm{MCH}$ alone inhibited synaptic transmission

\section{Functional implications of MCH-induced effects on} hypocretin/orexin neurons

It is essential to determine how the hypocretin/orexin and $\mathrm{MCH}$ systems integrate to exert complex functions and behaviors for which the LH is responsible. Hypocretin/orexin neurons have been demonstrated to be glutamatergic (Rosin et al., 2003). Our recent data suggest that cell bodies of hypocretin/orexin neurons are under intensive glutamatergic innervation, making these neurons easily activated, which is consistent with the role of hypocretin/orexin neurons in arousal (Horvath and Gao, 2005). Hypocretin-1 also initiates a positive feedback loop in neurons that synthesize this peptide ( $\mathrm{Li}$ et al., 2002). Therefore, coordinated control of the hypocretin/orexin system is required for the generation of optimal outputs. Previous data suggest that inhibitory metabotropic glutamate receptors provide one route of negative feedback to the hypocretin/orexin system in the LH (AcunaGoycolea et al., 2004); however, this negative feedback depends on glutamate released from the same presynaptic terminals resulting in a simple form of autoinhibition. Many other neurotransmitters/ 
modulators have been reported to regulate the activity of hypocretin/orexin neurons (Muraki et al., 2004; Bayer et al., 2005; Tsujino et al., 2005; Alberto et al., 2006; Xie et al., 2006; Yamanaka et al., 2006; Liu and Gao, 2007). Here, we demonstrate that $\mathrm{MCH}$ provides a unique mode of negative feedback to the hypocretin/orexin system in the LH, suggesting that the hypocretin/orexin system is under the modulation of its targets in the LH. MCH-mediated negative feedback may have a broader impact on the function of the LH.

Our results showing that $\mathrm{MCH}$ does not inhibit baseline action potential generation and synaptic transmission in hypocretin/ orexin neurons are particularly intriguing in that it seems to permit the easy activation of hypocretin/orexin neurons under resting conditions. It is tempting to postulate that hypocretin/orexin may act as the major excitatory factor in the $\mathrm{LH}$ because it may increase excitation in both the hypocretin/ orexin and $\mathrm{MCH}$ neurons (Li et al., 2002; van den Pol et al., 2004), whereas MCH acts to inhibit only when the excitation of the hypocretin/orexin system reaches a certain level, thus fine-tuning the final output of the LH. From an evolutionary perspective, such a system offers "checks and balances" to maintain the excitability necessary for the brain to function but prevent overexcitation that might compromise delicately controlled behaviors. This balance is particularly important for promoting positive energy homeostasis. $\mathrm{MCH}$ promotes food intake, whereas hypocretin/orexin promotes sufficient wakefulness to support food seeking and intake (Saper, 2006), leading to increased energy expenditure through increasing locomotor activity, sympathetic activity, cardiovascular function, and metabolic rates (Lubkin and Stricker-Krongrad, 1998; Matsumura et al., 2003; Sakurai, 2003). A balance or a set point determined by the state of the hypocretin/orexin and $\mathrm{MCH}$ systems is critical for energy intake and conservation. Any (genetic, environmental, or metabolic) changes that interfere with the balance could lead to overexcitation and altered behavior in animals, as may be the case in MCHR1 KO mice, which show increased locomotor activity, food intake, metabolic rate, and a lean phenotype (Marsh et al., 2002). Administration of exogenous hypocretin-1 or -2 into the lateral ventricle inducing hyperlocomotion, stereotypy, and grooming behavior in rats provides additional evidence in this direction (Nakamura et al., 2000). In summary, we have demonstrated a novel interaction between the hypocretin/orexin and $\mathrm{MCH}$ systems in the LH, which may not only be relevant to the roles of hypocretin/orexin and $\mathrm{MCH}$ in sleep/ arousal regulation and energy homeostasis but also to their roles in stress response and other brain functions.

\section{References}

Acuna-Goycolea C, Li Y, Van Den Pol AN (2004) Group III metabotropic glutamate receptors maintain tonic inhibition of excitatory synaptic input to hypocretin/orexin neurons. J Neurosci 24:3013-3022.

Ahnaou A, Drinkenburg WH, Bouwknecht JA, Alcazar J, Steckler T, Dautzenberg FM (2008) Blocking melanin-concentrating hormone MCH(1) receptor affects rat sleep-wake architecture. Eur J Pharmacol 579:177-188.
Alberto CO, Trask RB, Quinlan ME, Hirasawa M (2006) Bidirectional dopaminergic modulation of excitatory synaptic transmission in orexin neurons. J Neurosci 26:10043-10050.

Bächner D, Kreienkamp H, Weise C, Buck F, Richter D (1999) Identification of melanin concentrating hormone $(\mathrm{MCH})$ as the natural ligand for the orphan somatostatin-like receptor 1 (SLC-1). FEBS Lett 457:522-524.

Bayer L, Eggermann E, Serafin M, Grivel J, Machard D, Muhlethaler M, Jones BE (2005) Opposite effects of noradrenaline and acetylcholine upon hypocretin/orexin versus melanin concentrating hormone neurons in rat hypothalamic slices. Neuroscience 130:807-811.

Bittencourt JC, Presse F, Arias C, Peto C, Vaughan J, Nahon JL, Vale W, Sawchenko PE (1992) The melanin-concentrating hormone system of the rat brain: an immuno- and hybridization histochemical characterization. J Comp Neurol 319:218-245.

Borgland SL, Taha SA, Sarti F, Fields HL, Bonci A (2006) Orexin A in the VTA is critical for the induction of synaptic plasticity and behavioral sensitization to cocaine. Neuron 49:589-601.

Cai XJ, Widdowson PS, Harrold J, Wilson S, Buckingham RE, Arch JR, Tadayyon M, Clapham JC, Wilding J, Williams G (1999) Hypothalamic orexin expression: modulation by blood glucose and feeding. Diabetes 48:2132-2137.

Chambers J, Ames RS, Bergsma D, Muir A, Fitzgerald LR, Hervieu G, Dytko GM, Foley JJ, Martin J, Liu WS, Park J, Ellis C, Ganguly S, Konchar S, Cluderay J, Leslie R, Wilson S, Sarau HM (1999) Melanin-concentrating hormone is the cognate ligand for the orphan G-protein-coupled receptor SLC-1. Nature 400:261-265.

Chemelli RM, Willie JT, Sinton CM, Elmquist JK, Scammell T, Lee C, Richardson JA, Williams SC, Xiong Y, Kisanuki Y, Fitch TE, Nakazato M, Hammer RE, Saper CB, Yanagisawa M (1999) Narcolepsy in orexin knockout mice: molecular genetics of sleep regulation. Cell 98:437-451.

de Lecea L, Kilduff TS, Peyron C, Gao X, Foye PE, Danielson PE, Fukuhara C, Battenberg EL, Gautvik VT, Bartlett FS 2nd, Frankel WN, van den Pol AN, Bloom FE, Gautvik KM, Sutcliffe JG (1998) The hypocretins: 


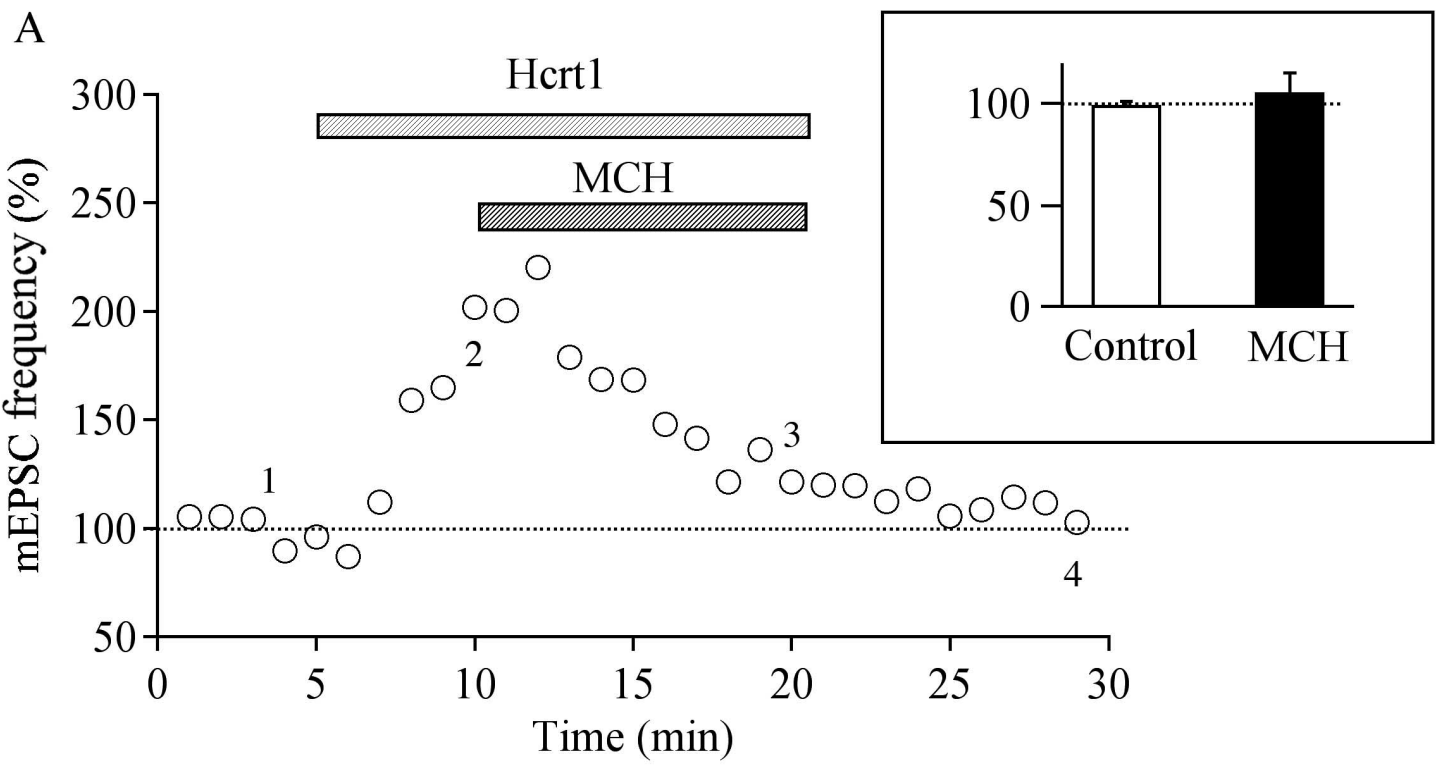

B

\section{1}

Control

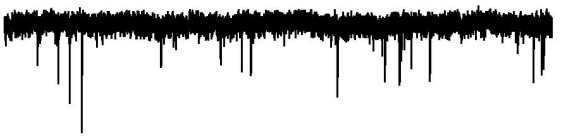

Hert1

2

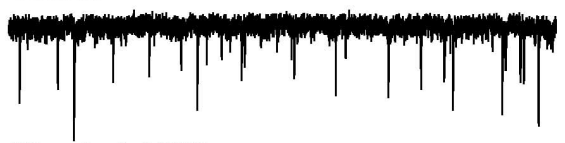

Hcrt1+MCH

3

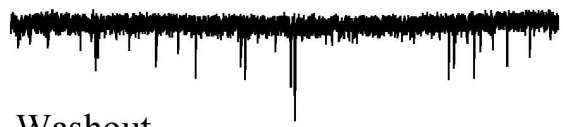

Washout

4

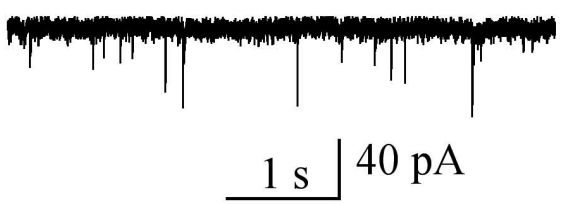

C

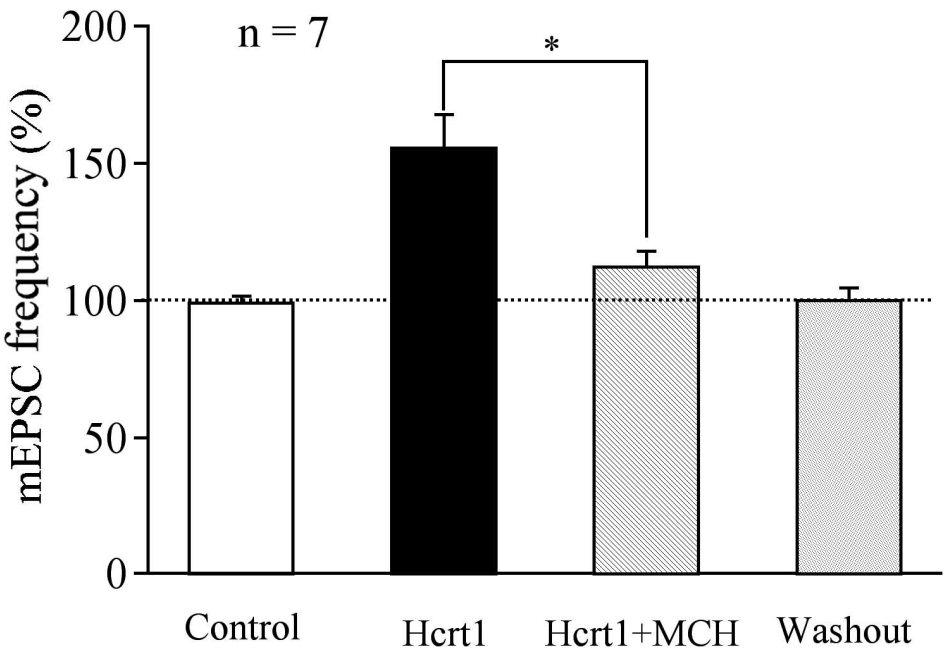

Figure 7. MCH depresses hypocretin-1-induced enhancement of the frequency of $m E P S C s$ in hypocretin/orexin neurons. After the increment in the frequency of $m E P S C s$ induced by hypocretin-1 reaches a plateau, $\mathrm{MCH}$ was applied to the recorded neurons in the presence of hypocretin-1. $A$, The time course of a typical experiment is presented. Inset, $\mathrm{A}$ bar graph indicates that $\mathrm{MCH}$ does not inhibit the basal frequency of $\mathrm{mEPSC}$ in hypocretin/orexin neurons. Time points at which raw traces were taken are indicated by 1-4. B, Sample traces of mEPSCs recorded in different phases of our experiments are shown. C, Pooled data from all seven hypocretin/orexin neurons show that the frequency of mEPSCs in the presence of MCH plus hypocretin-1 is significantly lower than that in the presence of hypocretin-1 alone. ${ }^{*} p<0.05$.

hypothalamus-specific peptides with neuroexcitatory activity. Proc Natl Acad Sci U S A 95:322-327.

Eggermann E, Bayer L, Serafin M, Saint-Mleux B, Bernheim L, Machard D, Jones BE, Mühlethaler M (2003) The wake-promoting hypocretinorexin neurons are in an intrinsic state of membrane depolarization. J Neurosci 23:1557-1562.

Gao XB, van den Pol AN (2001) Melanin concentrating hormone depresses synaptic activity of glutamate and GABA neurons from rat lateral hypothalamus. J Physiol 533:237-252.

Gao XB, van den Pol AN (2002) Melanin-concentrating hormone depresses L-, N-, and P/Q-type voltage-dependent calcium channels in rat lateral hypothalamic neurons. J Physiol 542:273-286.

Georgescu D, Sears RM, Hommel JD, Barrot M, Bolaños CA, Marsh DJ, Bednarek MA, Bibb JA, Maratos-Flier E, Nestler EJ, DiLeone RJ (2005) The hypothalamic neuropeptide melanin-concentrating hormone acts in the nucleus accumbens to modulate feeding behavior and forced-swim performance. J Neurosci 25:2933-2940.

Guan JL, Uehara K, Lu S, Wang QP, Funahashi H, Sakurai T, Yanagizawa M,
Shioda S (2002) Reciprocal synaptic relationships between orexin- and melanin-concentrating hormone-containing neurons in the rat lateral hypothalamus: a novel circuit implicated in feeding regulation. Int J Obes Relat Metab Disord 26:1523-1532.

Hanriot L, Camargo N, Courau AC, Leger L, Luppi PH, Peyron C (2007) Characterization of the melanin-concentrating hormone neurons activated during paradoxical sleep hypersomnia in rats. J Comp Neurol 505:147-157.

Harris GC, Wimmer M, Aston-Jones G (2005) A role for lateral hypothalamic orexin neurons in reward seeking. Nature 437:556-559.

Hawes BE, Kil E, Green B, O’Neill K, Fried S, Graziano MP (2000) The melanin-concentrating hormone receptor couples to multiple $\mathrm{G}$ proteins to activate diverse intracellular signaling pathways. Endocrinology 141:4524-4532.

Horvath TL, Gao XB (2005) Input organization and plasticity of hypocretin neurons: possible clues to obesity's association with insomnia. Cell Metab $1: 279-286$

Lembo PM, Grazzini E, Cao J, Hubatsch DA, Pelletier M, Hoffert C, St-Onge 
S, Pou C, Labrecque J, Groblewski T, O’Donnell D, Payza K, Ahmad S, Walker P (1999) The receptor for the orexigenic peptide melaninconcentrating hormone is a G-protein-coupled receptor. Nat Cell Biol 1:267-271.

Li Y, Gao XB, Sakurai T, van den Pol AN (2002) Hypocretin/Orexin excites hypocretin neurons via a local glutamate neuron-A potential mechanism for orchestrating the hypothalamic arousal system. Neuron 36:1169-1181.

Lin L, Faraco J, Li R, Kadotani H, Rogers W, Lin X, Qui X, de Jong PJ, Nishino S, Mignot E (1999) The sleep disorder canine narcolepsy is caused by a mutation in the hypocretin (orexin) receptor 2 gene. Cell 98:365-376.

Liu ZW, Gao XB (2007) Adenosine inhibits activity of hypocretin/orexin neurons by the $\mathrm{Al}$ receptor in the lateral hypothalamus: a possible sleeppromoting effect. J Neurophysiol 97:837-848.

Lubkin M, Stricker-Krongrad A (1998) Independent feeding and metabolic actions of orexins in mice. Biochem Biophys Res Commun 253:241-245.

Marsh DJ, Weingarth DT, Novi DE, Chen HY, Trumbauer ME, Chen AS, Guan XM, Jiang MM, Feng Y, Camacho RE, Shen Z, Frazier EG, Yu H, Metzger JM, Kuca SJ, Shearman LP, Gopal-Truter S, MacNeil DJ, Strack AM, MacIntyre DE, Van der Ploeg LH, Qian S (2002) Melanin-concentrating hormone 1 receptor-deficient mice are lean, hyperactive, and hyperphagic and have altered metabolism. Proc Natl Acad Sci U S A 99:3240-3245.

Matsumura K, Tsuchihashi T, Fujii K, Iida M (2003) Neural regulation of blood pressure by leptin and the related peptides. Regul Pept 114:79-86.

Messina MM, Overton JM (2007) Cardiovascular effects of melaninconcentrating hormone. Regul Pept 139:23-30.

Modirrousta M, Mainville L, Jones BE (2005) Orexin and MCH neurons express c-Fos differently after sleep deprivation vs. recovery and bear different adrenergic receptors. Eur J Neurosci 21:2807-2816.

Muraki Y, Yamanaka A, Tsujino N, Kilduff TS, Goto K, Sakurai T (2004) Serotonergic regulation of the orexin/hypocretin neurons through the 5-HT1A receptor. J Neurosci 24:7159-7166.

Nakamura T, Uramura K, Nambu T, Yada T, Goto K, Yanagisawa M, Sakurai $\mathrm{T}$ (2000) Orexin-induced hyperlocomotion and stereotypy are mediated by the dopaminergic system. Brain Res 873:181-187.

Narita M, Nagumo Y, Hashimoto S, Narita M, Khotib J, Miyatake M, Sakurai T, Yanagisawa M, Nakamachi T, Shioda S, Suzuki T (2006) Direct involvement of orexinergic systems in the activation of the mesolimbic dopamine pathway and related behaviors induced by morphine. J Neurosci 26:398-405.

Nishino S, Ripley B, Overeem S, Lammers GJ, Mignot E (2000) Hypocretin (orexin) deficiency in human narcolepsy. Lancet 355:39-40.

Peyron C, Tighe DK, van den Pol AN, de Lecea L, Heller HC, Sutcliffe JG, Kilduff TS (1998) Neurons containing hypocretin (orexin) project to multiple neuronal systems. J Neurosci 18:9996-10015.

Pissios P, Trombly DJ, Tzameli I, Maratos-Flier E (2003) Melaninconcentrating hormone receptor 1 activates extracellular signal-regulated kinase and synergizes with $\mathrm{G}(\mathrm{s})$-coupled pathways. Endocrinology 144: 3514-3523.

Qu D, Ludwig DS, Gammeltoft S, Piper M, Pelleymounter MA, Cullen MJ, Mathes WF, Przypek R, Kanarek R, Maratos-Flier E (1996) A role for melanin-concentrating hormone in the central regulation of feeding behaviour. Nature 380:243-247.

Rao Y, Liu ZW, Borok E, Rabenstein RL, Shanabrough M, Lu M, Picciotto MR, Horvath TL, Gao XB (2007) Prolonged wakefulness induces experience-dependent synaptic plasticity in mouse hypocretin/orexin neurons. J Clin Invest 117:4022-4033.

Rosin DL, Weston MC, Sevigny CP, Stornetta RL, Guyenet PG (2003) Hypothalamic orexin (hypocretin) neurons express vesicular glutamate transporters VGLUT1 or VGLUT2. J Comp Neurol 465:593-603.

Saito Y, Maruyama K (2006) Identification of melanin-concentrating hormone receptor and its impact on drug discovery. J Exp Zoolog A Comp Exp Biol 305:761-768.

Saito Y, Nothacker HP, Wang Z, Lin SH, Leslie F, Civelli O (1999) Molecular characterization of the melanin-concentrating-hormone receptor. Nature 400:265-269.

Sakurai T (2003) Orexin: a link between energy homeostasis and adaptive behaviour. Curr Opin Clin Nutr Metab Care 6:353-360.

Sakurai T, Amemiya A, Ishii M, Matsuzaki RM, Chemelli RM, Tanaka H, Williams SC, Richardson JA, Kozlowski GP, Wilson S, Arch JR, Buckingham RE, Haynes AC, Carr SA, Annan RS, McNulty DE, Liu WS, Terrett JA, Elshourbagy NA, Bergsma DJ, Yanagisawa M (1998) Orexins and orexin receptors: a family of hypothalamic neuropeptides and G proteincoupled receptors that regulate feeding behavior. Cell 92:573-585.

Samson WK, Bagley SL, Ferguson AV, White MM (2007) Hypocretin/ orexin type 1 receptor in brain: role in cardiovascular control and the neuroendocrine response to immobilization stress. Am J Physiol Regul Integr Comp Physiol 292:R382-387.

Saper CB (2006) Staying awake for dinner: hypothalamic integration of sleep, feeding, and circadian rhythms. Prog Brain Res 153:243-252.

Sawchenko PE (1998) Toward a new neurobiology of energy balance, appetite, and obesity: the anatomists weigh in. J Comp Neurol 402:435-441.

Scammell TE, Estabrooke IV, McCarthy MT, Chemelli RM, Yanagisawa M, Miller MS, Saper CB (2000) Hypothalamic arousal regions are activated during modafinil-induced wakefulness. J Neurosci 20:8620-8628.

Segal-Lieberman G, Bradley RL, Kokkotou E, Carlson M, Trombly DJ, Wang X, Bates S, Myers MG Jr, Flier JS, Maratos-Flier E (2003) Melaninconcentrating hormone is a critical mediator of the leptin-deficient phenotype. Proc Natl Acad Sci U S A 100:10085-10090.

Shi Y (2004) Beyond skin color: emerging roles of melanin-concentrating hormone in energy homeostasis and other physiological functions. Peptides 25:1605-1611.

Simon P, Panissaud C, Costentin J (1994) The stimulant effect of modafinil on wakefulness is not associated with an increase in anxiety in mice. Psychopharmacology 114:597-600.

Smith DG, Tzavara ET, Shaw J, Luecke S, Wade M, Davis R, Salhoff C, Nomikos GG, Gehlert DR (2005) Mesolimbic dopamine super-sensitivity in melanin-concentrating hormone-1 receptor-deficient mice. J Neurosci 25:914-922.

Smith DG, Davis RJ, Rorick-Kehn L, Morin M, Witkin JM, McKinzie DL, Nomikos GG, Gehlert DR (2006) Melanin-concentrating hormone-1 receptor modulates neuroendocrine, behavioral, and corticolimbic neurochemical stress responses in mice. Neuropsychopharmacology 31:1135-1145.

Smith DG, Qi H, Svenningsson P, Wade M, Davis RJ, Gehlert DR, Nomikos GG (2008) Behavioral and biochemical responses to d-amphetamine in $\mathrm{MCH} 1$ receptor knockout mice. Synapse 62:128-136.

Sutcliffe JG, de Lecea L (2000) The hypocretins: excitatory neuromodulatory peptides for multiple homeostatic systems, including sleep and feeding. J Neurosci Res 62:161-168.

Tsujino N, Yamanaka A, Ichiki K, Muraki Y, Kilduff TS, Yagami K, Takahashi S, Goto K, Sakurai T (2005) Cholecystokinin activates orexin/hypocretin neurons through the cholecystokinin A receptor. J Neurosci 25:7459-7469.

van den Pol AN, Gao XB, Obrietan K, KilduffTS, Belousov AB (1998) Pre- and postsynaptic actions and modulation of neuroendocrine neurons by a new hypothalamic peptide, hypocretin/orexin. J Neurosci 18:7962-7971.

van den Pol AN, Acuna-Goycolea C, Clark KR, Ghosh PK (2004) Physiological properties of hypothalamic MCH neurons identified with selective expression of reporter gene after recombinant virus infection. Neuron 42:635-652.

Verret L, Goutagny R, Fort P, Cagnon L, Salvert D, Léger L, Boissard R, Salin P, Peyron C, Luppi PH (2003) A role of melanin-concentrating hormone producing neurons in the central regulation of paradoxical sleep. BMC Neurosci 4:19.

Winsky-Sommerer R, Boutrel B, de Lecea L (2005) Stress and arousal: the corticotrophin-releasing factor/hypocretin circuitry. Mol Neurobiol 32:285-294.

Xie X, Crowder TL, Yamanaka A, Morairty SR, Lewinter RD, Sakurai T, KilduffTS (2006) GABA(B) receptor-mediated modulation of hypocretin/orexin neurones in mouse hypothalamus. J Physiol (Lond) 574:399-414.

Yamanaka A, Beuckmann CT, Willie JT, Hara J, Tsujino N, Mieda M, Tominaga M, Yagami K, Sugiyama F, Goto K, Yanagisawa M, Sakurai T (2003) Hypothalamic orexin neurons regulate arousal according to energy balance in mice. Neuron 38:701-713.

Yamanaka A, Muraki Y, Ichiki K, Tsujino N, Kilduff TS, Goto K, Sakurai T (2006) Orexin neurons are directly and indirectly regulated by catecholamines in a complex manner. J Neurophysiol 96:284-298.

Zhang W, Shimoyama M, Fukuda Y, Kuwaki T (2006) Multiple components of the defense response depend on orexin: evidence from orexin knockout mice and orexin neuron-ablated mice. Auton Neurosci 126127:139-145.

Zhou D, Shen Z, Strack AM, Marsh DJ, Shearman LP (2005) Enhanced running wheel activity of both Mch1r- and Pmch-deficient mice. Regul Pept 124:53-63. 